\title{
«El deber de mejorar»: Higiene e identidad obrera en el socialismo madrileño, 1884-1904
}

\author{
Ricardo Campos (*) \\ (*) Instituto de Historia. Centro de Ciencias Humanas y Sociales. CSIC. Madrid. \\ ricardo.campos@cchs.csic.es
}

Dynamis

[0211-9536] 2011; $31(2): 497-526$
Fecha de recepción: 5 de marzo de 2010

Fecha de aceptación: 4 de diciembre de 2010

SUMARIO: 1.-Introducción. 2.-Desigualdad social y enfermedad en el discurso socialista. 3.-La higiene, instrumento de dignificación obrera. 4.-Conclusión.

RESUMEN: Se pretende analizar la modulación y transformaciones de los discursos y reivindicaciones socialistas en materia sanitaria durante el periodo comprendido entre 1883 y 1904, con el objeto de demostrar su alto grado de politización y su deseo de integración social y política. En este sentido, se analiza el papel político desempeñado por la salud y la higiene en la construcción de una identidad obrera, así como la tensión y las ambigüedades ideológicas generadas por la necesidad de apropiarse de un discurso ajeno, emitido desde la ciencia, pero necesario para conseguir plantear reivindicaciones que perseguían la inclusión social de los obreros como ciudadanos de pleno derecho y su dignificación.

PALABRAS CLAVE: Socialismo, higiene, salud, dignidad, identidad.

KEY WORDS: Socialism, hygiene, health, dignity, identity.

\section{Introducción $(*)$}

En octubre 1899 desde las páginas de El Liberal, el Dr. Felipe Ovilo relacionaba la desidia de las Sociedades Obreras de Madrid hacía el «arte de conservar la salud y la vida» con la elevada contribución de los obreros al aumento de la cifra de mortalidad de esta pobre nación. A su juicio las organizaciones obreras estaban demasiado preocupadas por elevar la ins-

(*) Trabajo realizado en el marco del Proyecto de Investigación HAR2009-13389-C03-02 (subprograma HIST), financiado por la Subdirección General de Proyectos de Investigación del MCINN. 
trucción de los trabajadores y poco por mejorar las condiciones higiénicas del trabajo, principal causa de los accidentes laborales y de las enfermedades profesionales. Ante ello, instaba a los obreros a presionar a los gobiernos para que cumplieran la legislación laboral y les protegiera de los peligros que les acechaban ${ }^{1}$.

Las críticas de Ovilo no eran ciertas ni inocentes. La salud, la higiene y la lucha contra la enfermedad eran cuestiones importantes para los socialistas desde su constitución en fuerza política, pues estaban íntimamente ligadas a sus reivindicaciones de mejora de las condiciones de vida y trabajo de la clase obrera. Además, fruto del cambio de estrategia política del PSOE, iniciado a mediados de la década de 1890, la preocupación de los socialistas por estos asuntos en los años que marcan el paso del siglo XIX al XX se transformó y materializó en un activa política de demanda de reformas sociales que cristalizó en su participación desde 1904 en el Instituto de Reformas Sociales. El impulso político a la demanda de reformas sociales estuvo acompañado de una relectura del papel de la higiene como instrumento de mejora de la condición física y moral de los obreros y de dignificación de la clase obrera frente al cuestionamiento de su moralidad por parte de la burguesía. La organización de cursos y conferencias de higiene y la fundación en 1904 de la Mutualidad Obrera Médico-Farmaceútica fueron dos importantes exponentes de este cambio de actitud ${ }^{2}$. Todo ello - demandas de reformas sociales y resignificación de la higiene- se produjo además en el marco de una creciente exigencia de ampliación de los derechos sociales

1. Crónicas de Higiene Vulgar. El Liberal. 30 Oct 1899; (7332): 2.

2. El objetivo de la Mutualidad Obrera Médico-Farmacéutica era garantizar a los obreros afiliados la asistencia sanitaria que el sistema asistencial estatal era incapaz de dar a los trabajadores Existen muy pocos trabajos sobre la Mutualidad Obrera. Sin embargo, en los últimos años ha merecido la atención de los historiadores, si bien todavía su estudio tiene un largo recorrido. Véase al respecto: Castillo, Santiago; Campos Marín, Ricardo. Services mutualistes de santé: conceptions et réalités ouvrières au premier tiers du XXe siècle. Assayag, Dominique; Guedj, François; Pinault, Michel; Toucas-Truyen, Patricia, eds. L'approche mutualiste de la santé en Europe. Actions de prévention et services à la personne. Paris: Alternatives économiques; 2005 pp. 63-71; León Sanz, Pilar. Profesión y asistencia médico-farmacéutica en los escritos de Jaime Vera (1859-1918). Dynamis. 2006; 26: 169-193; Castillo, Santiago. La Mutualidad Obrera Médico-Farmacéutica y el socialismo madrileño en el primer tercio del siglo XX. In: Centenario de la Casa del Pueblo de Madrid. Madrid: Sociedad Estatal de Conmemoraciones Culturales SECC, UGT Madrid, Fundación Progreso y Cultura; 2008, p. 243-249; Macias Gómez, Escolástica. La educación obrera y su proyección en la sociedad. Centenario de la Casa del Pueblo 1908-2008. Un siglo del sindicato UGT en Madrid. Madrid: Editorial Universitas, 2008, 164-172. 
y políticos de los obreros que anhelaban su integración en el sistema como ciudadanos de pleno derecho ${ }^{3}$.

Como es bien sabido, a raíz de los importantes desajustes socio-económicos que acarreó el proceso de industrialización durante el siglo XIX, surgió un importante movimiento higienista que defendió la importancia de la medicina como ciencia social destinada al buen gobierno de los pueblos. Los higienistas constataron una serie de problemas íntimamente ligados a la salud como la extensión de la miseria entre los trabajadores, la diferente morbi-mortalidad entre ricos y pobres, las penosas condiciones de trabajo y de vida de las clases populares, así como la aparición de nuevas patologías ligadas a dichas condiciones. Las soluciones que propusieron para paliar estos problemas oscilaron entre el saneamiento del medio obrero y su moralización, despojando así de incómodas derivas las carencias de salud de la población. En este sentido, transformaron las causas sociales de la miseria y de la enfermedad en un problema moral cuyo origen residía en la naturaleza viciosa de los trabajadores y en sus formas de vida. Asimismo, lo higienistas al defender el papel de la higiene como árbitro del conflicto social, se erigieron en agentes de la racionalización y disciplinamiento de las clases populares y de su integración en la nueva sociedad industrial. La salud fue el concepto, aparentemente neutral y científico que sirvió como instrumento ideológico para conseguir dichos objetivos ${ }^{4}$.

3. Castillo, Santiago. Juan José Morato. La actitud del socialismo ante la extensión universitaria del profesorado ovetense. In: Uría, Jorge, coord. Institucionismo y reforma social en España. Madrid: Talasa; 2000, p. 162-183.

4. Sobre el higienismo y la percepción de la higiene y sus conexiones con la moral existe una exhaustiva bibliografía. Labisch, Alfons. Doctors, workers and the scientific cosmology of the industrial word: The social construction of «Health» an the «Homo Hygienicus». Journal of Contemporany History. 1985; 20: 599-615. Labisch, Alfons. Hygiene ist moral - moral ist Hygiene. Soziale Disziplinierung durch Ärzte und Medizin. In: C. Sachsse; F. Temstedt, eds. Soziale sicherheit und soziale Disziplinierung. Beitrige zureiner historischen Theorie der Sozialpolitik. Frankfurt: Suhrkarnp; 1986, p. 265-285; Para el caso español sirvan como muestra: Rodríguez Ocaña, Esteban. La constitución de la Medicina social como disciplina en España (1882-1923), Madrid, Ministerio de Sanidad y Consumo, 1987; Rodríguez Ocaña, Esteban. Paz, trabajo, higiene. Los enunciados acerca de la higiene industrial en la España del siglo XIX. In: Huertas, Rafael; Campos Marín, Ricardo, coords. Medicina Social y clase obrera en España. (Siglos XIX y XX), Madrid: FIM; 1992, vol. 2, p. 383-406; Campos Marín, Ricardo. La sociedad enferma: Higiene y moral en España en la segunda mitad del siglo XIX y principios del XX. Hispania. 1995; 55 (3): 1093-1112; Gónzalez de Pablo, Angel. Sobre la configuración del modelo de pensamiento de la higiene actual: el caso español. Dynamis. 1995; 15: 267-299. 
Frente a la insistencia de los higienistas en responsabilizar a las víctimas de las enfermedades de su propio mal, así como en articular como principal estrategia para la erradicación y prevención de las mismas el cambio de costumbres y de estilo de vida del proletariado, sin mostrar gran interés por la corrección de los factores sociales que las provocaban, los socialistas externalizaron las causas de la situación que padecían los obreros, acusando a la burguesía y al capitalismo como los principales responsables. Sus interpretaciones de la realidad social chocaban frontalmente con las ideas que subyacían en el seno del movimiento higienista al sustraer a la salud de sus connotaciones neutrales y convertirla en un instrumento de lucha política.

Pese a los intentos de los médicos por descalificar los discursos y propuestas socialistas en materia de salud e higiene, y a las invectivas de estos últimos contra el sistema capitalista cuando analizaban la situación sanitaria de la clase obrera, existieron, no sin tensiones y críticas, espacios de negociación y de cooperación entre ambas partes que les obligaron a modular algunas de sus posiciones.

El estudio de las fuentes obreras, en nuestro caso socialistas, pone de relieve la existencia de un contradiscurso que cuestiona la visión hegemónica de la medicina sobre la salud y la higiene, matizando y reinterpretando sus postulados o, en ocasiones tomando la forma de resistencias más o menos abiertas 5 . Por otra parte, el análisis de este tipo de fuentes, matiza los estudios historiográficos realizados con fuentes exclusivamente médicas y administrativas, que han dado lugar, en palabras de Rodríguez Ocaña, a interpretaciones estrechas de lo social en medicina que la han reducido «a la historia de la sociedad de los médicos» ${ }^{6}$. También rebate los trabajos focalizados en el control social y en la colonización de los grupos subalternos que suelen obviar su capacidad de reacción, de resistencia, de negociación y de producción de un discurso propio ${ }^{7}$. La exploración meticulosa de las

5. A este respecto véase la propuesta de Jiménez-Lucena, Isabel y Molero-Mesa, Jorge. Problematizando el proceso de (des)medicalización. Mecanismos de sometimiento/Autogestión del cuerpo en los medios libertarios españoles del primer tercio del siglo XX. In: Miranda, Marisa; Girón Sierra, Álvaro, coords. Cuerpo, biopolítica y control social. América Latina y Europa en los siglos XIX y XX. Buenos Aires: Siglo XXI de Argentina; 2009, p. 69-93

6. Rodríguez Ocaña, Esteban. La protección de la salud en los dos últimos siglos del estado español. Una evaluación histórica. In: Nash; Mary; Ballester, Rosa, eds. Mulheres, trabalho e reproduçao. Attitudes sociais e politicas de protecçao à vida. Actas do III Congresso da ADEH, Porto, Ediçoes Afrontamento; 1996, vol. 2, p. 139-155:139

7. Un buen ejemplo de estas tesis puede verse en Álvarez Uría, Fernando. Miserables y locos. Medicina mental y Orden social en la España del siglo XIX, Barcelona: Tusquets; 1983. 
fuentes socialistas y su encuadramiento en un marco interpretativo diferente permiten mostrar un proceso menos lineal y mucho más complejo y problemático en el que las contradicciones y las tensiones, tanto internas como interclasistas asoman claramente.

En esta línea, propongo interpretar el discurso sanitario socialista como fuente de argumentos para denunciar el sistema capitalista y proclamar la necesidad de transformarlo y como expresión de un anhelo de elevación moral, dignificación y de integración social de los trabajadores como ciudadanos de pleno derecho ${ }^{8}$.

A mi juicio, las reivindicaciones y concepciones en materia de salud y de higiene de los socialistas españoles pueden leerse como una lucha por la ampliación de los derechos sociales y políticos de los trabajadores, y como un elemento esencial de dignificación de la clase obrera, ligado al proceso de construcción de una conciencia socialista íntimamente vinculada a la mejora moral y a la educación obrera. La aceptación, a partir de mediados de la década de 1890, por los socialistas de la higiene y la salud como principios rectores del comportamiento de los obreros, fue, como intentaré demostrar, un instrumento, con alto valor simbólico, de defensa del proletariado ante el discurso estigmatizador de la burguesía, que tomó forma en un modelo de obrero utópico, el obrero sano, consciente de sus deberes y revolucionario, frente al modelo burgués del obrero irresponsable e inculto que precisaba ser tutelado.

Para ello analizaré, a partir del estudio de los informes obreros ante la Comisión de Reformas Sociales, de El Socialista y de La Nueva Era, la modulación y transformaciones de los discursos y reivindicaciones socialistas en materia sanitaria durante el periodo comprendido entre 1883 y 1904, con el objeto de demostrar su alto grado de politización y su deseo de integración social y política. Dicho periodo resulta especialmente interesante pues, durante el mismo, el socialismo español pasó de una perspectiva ideológica revolucionaria a otra de corte reformista que metamorfoseó su visión de la higiene. Tomaré también como elementos de análisis el papel político desempeñado por la salud y la higiene en la construcción de una identidad obrera, así como la tensión y las ambigüedades ideológicas generadas por

8. Sobre el anhelo del PSOE a comienzos del siglo XX por integrar a la clase obrera en un sistema democrático pueden verse Castillo, n. 3, p. 170-183; Castillo, Santiago. Trabajadores, ciudadanía y reforma social en España: Juan José Morato (1864-1938). Madrid: Siglo XXI; 2005, vol. 1, p. 71-83. 
la necesidad de apropiarse de un discurso ajeno, emitido desde la ciencia, pero necesario para conseguir plantear reivindicaciones que perseguían la inclusión social de los obreros como ciudadanos de pleno derecho.

\section{Desigualdad social y enfermedad en el discurso socialista}

El 5 de diciembre de 1883 se creaba en España la Comisión de Reformas Sociales con el objeto de estudiar «las cuestiones que interesan a la mejora o bienestar de las clases obreras». Para alcanzar esos objetivos político-sociales la Comisión abrió una gran encuesta en todo el Estado en la que podían participar los individuos y sociedades que desearan contestar el formulario remitido. Una parte sustancial del cuestionario tenía que ver directamente con las condiciones de vida y trabajo de la clase obrera ${ }^{9}$. Las respuestas que fueron remitidas por escrito o recogidas en sesiones públicas y orales no respondieron a las expectativas de los promotores de la iniciativa, pues muchas provincias no enviaron los informes recopilados, en otras no se dejó participar a la clase obrera, o como en el caso de los anarquistas se negaron a participar en lo que consideraban una pantomima ${ }^{10}$. La información obtenida en Madrid fue importante, en especial desde el punto de vista obrero, pues el Partido Socialista y los representantes de las sociedades de trabajadores acudieron a informar sobre su situación para denunciar las condiciones de explotación de los obreros y airear públicamente el ideario

9. Sobre la Comisión de Reformas Sociales pueden consultarse las siguientes obras. Castillo, Santiago. Estudio introductorio. In: Reformas Sociales. Información oral y escrita publicada de 1889 a 1893. Madrid: Ministerios de Trabajo y Seguridad Social; 1985, vol. 1, p. XIX-CLXIV; De la Calle, Maria Dolores. La Comisión de Reformas Sociales 1883-1903. Política social y conflicto de intereses en la España de la Restauración, Madrid: Ministerio de Trabajo y Seguridad Social; 1989; Montoya Tamayo, María Angeles; Frías Fernández, Juan Carlos et al. La condición obrera hace un siglo. Los trabajadores madrileños y la Comisión de Reformas Sociales. Madrid: Ediciones de la Universidad Autónoma de Madrid; 1991. Robles Muñoz, Cristobal. La condición moral de los obreros en los informes de la Comisión de Reformas Sociales, 1884-1886. Revista de Política Social. 1984; 142: 79-109; Álvarez Junco, José. La Comisión de Reformas Sociales: Intentos y realizaciones. In: Cuatro siglos de acción social. De la beneficencia al bienestar social, Madrid: Consejo General de Colegios Oficiales de Diplomados en Trabajo Social y Asistentes Sociales; 1986, p. 147-154; Pérez Ledesma, Manuel. La Comisión de Reformas Sociales y la cuestión social durante la Restauración. In: Cuatro siglos de acción social. De la beneficencia al bienestar social, Madrid: Consejo General de Colegios Oficiales de Diplomados en Trabajo Social y Asistentes Sociales; 1986, p. 155-166.

10. Castillo, n. 9, p. CX-CXI 
de su Partido. Ideario que en la década de 1880 se fundamentaba en la ley de bronce de los salarios formulada por Jules Guesde que preconizaba la progresiva miseria de la clase obrera y la división de la sociedad en dos clases antagónicas: burgueses y proletarios. Desde estos postulados ideológicos, el rechazo al reformismo fue el eje de la estrategia del socialismo español en su periodo fundacional. Sólo la revolución protagonizada por los trabajadores, liberaría a éstos de la explotación y la miseria al implantar el colectivismo como nueva forma de organización socioeconómica ${ }^{11}$. Este espíritu impugnador del sistema fue el que alimentó los informes de Pablo Iglesias, Jaime Vera y Antonio García Quejido a la Comisión de Reformas Sociales.

A pesar del maximalismo de sus posiciones y al carácter genérico de los informes escritos remitidos a la Comisión, los informes orales de los obreros aportaron datos concretos de la explotación cotidiana en el trabajo y de sus condiciones de vida, que vinculaban nítidamente con la salud y la enfermedad. Un dato importante es que a pesar de ser informes altamente ideologizados, introducían la propia experiencia ante el hecho de enfermar, dotando a su relato de una gran cercanía emocional y autenticidad, que les confiere un importante valor como fuente ${ }^{12}$.

La enfermedad se revelaba en las respuestas obreras como un elemento cotidiano no deseado y no como una fatalidad ante la que no cabía respuesta, lo que corrobora un cierto grado de instrucción y de conciencia política. Su origen social apuntaba con claridad a la injusta organización socio económica vigente que llevaba implícita su condena. Evidentemente desde tales postulados, quedaba claro que cuando los obreros hablaban de enfermedad no hablaban necesariamente de lo mismo que los médicos y reformadores burgueses. En esta línea, una cuestión que salió a colación en varios informes fueron las relaciones entre las condiciones de trabajo y la enfermedad. Este discurso sobre los orígenes sociales de la enfermedad

11. Arranz, Luis. El guedismo de Pablo Iglesias en los informes a la Comisión de Reformas Sociales. Estudios de Historia Social. 1979; 8-9: 207-216. Elorza, Antonio. Los esquemas socialistas de Pablo Iglesias. In: Elorza, Antonio; Ralle, Michel, eds. La formación del PSOE. Madrid: Crítica; 1989, p. 299-352.

12. En este sentido, este tipos de informes, a nuestro juicio, se aproximan a las autobiografias de los obreros alemanes, por su estílo directo y subjetivo, estudiadas por Stollberg. Stollberg, Gunnar. Industrialization and the construction of health risks in German workers'. Autobiographies from the late 19th and early 20th centuries. Dynamis. 1993; 13: 235-246; Stollberg, Gunnar. Natural and deliberate health. Coping with health in German autobiographies from the 18th and 19th centuries. Dynamis. 1997; 17: 193-211. 
era compartido también por obreros que no eran militantes socialistas y que abogaban por un entendimiento entre las diferentes clases sociales. Precisamente algunas de las intervenciones más sugerentes en este sentido provenían de los representantes de la Sociedad de Canteros que no estaba controlada por el PSOE. Así Vicente Recarte, cuya intervención ante la Comisión fue recogida con alivio por la prensa burguesa por considerarla razonable, frente a las «diatribas» socialistas, respondía con ironía a la pregunta 27 del formulario sobre higiene y salubridad en el trabajo:

«Respecto a la salubridad de los talleres, los cajistas se quejaban aquí amargamente en la primera información porque sus talleres estaban bajo cubierto. Pues nosotros a las siete de la mañana en este tiempo tenemos que ir a romper el hielo de las herramientas con la mano, y aguantar el sol cuando sale, y el agua cuando llueve; y no hay más remedio que sufrirlo, sin otro amparo que trozos de estera de la que destroza esa clase que nos explota. ¿Es esto salubridad? Ellos dirán que sí, porque naturalmente allí nos da bien el aire» ${ }^{13}$.

Otro compañero suyo de la Sociedad de Canteros, Villegas, era todavía más explícito al respecto al afirmar ante la Comisión:

«He visto a un individuo llegar a las siete de la mañana, encontrarse con una laguna y ponerse a quitar el agua. Llegó el amo y le dijo: "yo no pago el jornal por sacar agua, sino por labrar piedra”. Pues no tuvo más remedio que hacerlo, porque los amos ponen al trabajador en un precipicio; el trabajador tiene que optar entre no trabajar, y por consiguiente no comer o trabajar exponiéndose a coger un reuma o cualquiera otra enfermedad; pero esto tiene al amo sin cuidado, porque toma otro trabajador y en paz» ${ }^{14}$.

Las descripciones de las malas condiciones de trabajo se repiten en casi todos los informantes obreros con independencia del ramo al que pertenecían y de su militancia política. Sin embargo, las de los tipógrafos madrileños, claramente ubicados en el ámbito de influencia socialista, serán especialmente duras con los principales periódicos de la capital. Locales estrechos, utilización de materiales tóxicos, falta de ventilación, escasa iluminación, ruido, etc., son algunos de los asuntos que sacarán a

13. Reformas Sociales. Información oral y escrita publicada de 1889 a 1893. Madrid: Ministerios de Trabajo y Seguridad Social; 1985, vol. 1, p. 86.

14. Reformas Sociales, n. 13, p. 95 
colación los informantes del Montepío de Tipógrafos y de la Asociación del Arte de Imprimir ${ }^{15}$.

Otra cuestión importante que los informantes obreros se encargaron de poner en primer plano fueron los riesgos que para la salud representaba su condición de trabajadores. Así, el mencionado Villegas, señalaba que «el obrero que no muere desnucado muere reventado del trabajo o envenenado por lo que come y bebe, la atmósfera le molesta en todas partes; de nada disfruta más que si acaso del sol y eso porque no se le puede impedir ${ }^{16}$.

Por su parte, Saturnino García de la sección de maderas La Unión, ubicada en el ámbito socialista, cuando hablaba de los inválidos del trabajo contaba su estremecedora experiencia para criticar la desprotección que estos padecían:

«La suerte de los inválidos del trabajo es terrible, señores. Fijaos en mi: yo llevo treinta y cuatro o treinta y seis años trabajando, y hoy, a pesar de que hace cuatro que la Facultad médica me ha prohibido que trabaje, no tengo más remedio, si quiero poder llenar algún tanto el estómago de pan, por que no es suficiente el jornal que gana un hijo que tengo: no tengo más remedio que, muerto, de dolores, el día que por casualidad puedo proporcionarme un jornal ir a ganarlo» ${ }^{17}$.

La enfermedad, la invalidez y la vejez eran vividas como amenazas, porque traían aparejada la pérdida temporal o definitiva del trabajo y por ende un mayor empobrecimiento de la familia. Emilio Cortés de la Sociedad Montepío de Tipógrafos razonaba de la siguiente manera cuando se refería a la condición de los ancianos:

«Si trabajando la familia obrera no gana más que lo escasamente necesario para vivir; y digo para vivir, porque trabaja a la fuerza, porque hay quién trabaja con calentura, porque prefiere morir de calentura a morir de inanición; si trabajando en buen estado de salud no gana más de lo necesario para medio alimentarse, ¿Qué le ocurrirá cuando se la grava con una carga de esta naturaleza?» ${ }^{18}$.

\footnotetext{
15. Reformas Sociales, n. 13, p. 23-78.

16. Reformas Sociales, n. 13, p. 99.

17. Reformas Sociales, n. 13, p. 172.

18. Reformas Sociales, n. 13, p. 30.
} 
La concepción de la enfermedad latente en la mayoría de los informes obreros superaba con creces el estrecho marco trazado por la medicina. La preocupación por la pérdida del trabajo se situaba en el centro mismo del pensamiento sobre la enfermedad que tenían los obreros conscientes hasta el punto de establecer un círculo vicioso entre ambos, porque como el tipógrafo Hipólito Pauly explicaba a la Comisión con la falta de trabajo:

«Ya no hay casa, ya no hay para comer (...) y [el obrero] se ve precisado a comprar lo peor en el mercado y deshacerse de su ropa. De aquí como consecuencia lógica, viene la enfermedad ${ }^{19}$.

Estos testimonios y otros muchos, expresan la conciencia que los obreros organizados tenían de la estrecha relación existente entre su condición de trabajadores y los riesgos para la salud. Ni siquiera los análisis más agudos de la medicina decimonónica lograron establecer dicha relación de manera tan clara, pues en general los médicos fueron incapaces de superar la mera relación entre las insalubres condiciones de vida y de trabajo con la predisposición a la enfermedad. Mientras los obreros asumían que su condición de trabajadores era la causa de su falta de salud, y la expresión de la explotación y de la desigualdad que entrañaba el sistema capitalista, los médicos e higienistas focalizaban los problemas de salud de los trabajadores en cuestiones morales y ambientales. Lógicamente esta divergencia esencial tenía consecuencias en los planteamientos de unos y otros tanto a la hora de entender lo que era la salud y la enfermedad como de proponer medidas para combatirla. Esta dramática conclusión será un lugar común de las comparencias obreras en la Comisión de Reformas Sociales, y tendrá su expresión más contundente en las palabras del socialista Perezagua, representante de la Sociedad el Porvenir de Obreros del Metal que, con gran crudeza dirá: «Desde que voy a trabajar pesa sobre mi cabeza una sentencia de muerte: que me coja un correón; que me den un puntapié cuando no haya obra, y me muera de hambre ${ }^{20}$ ».

Los socialistas, al marcar el acento, no sólo en las insalubres condiciones de trabajo y de vida sino en la propia condición de trabajador como causa de la enfermedad, ponían en entredicho la visión unilateral y hegemónica de la medicina en cuestiones de salud e higiene, generando un contradis-

19. Reformas Sociales, n. 13, p. 55.

20. Reformas Sociales, n. 13, p. 181. 
curso en el que la salud adquiría un alto contenido político y reivindicativo. La supuesta neutralidad del higienismo y de la salud como valor supremo daba paso a una impugnación del sistema socioeconómico vigente. Todas las enfermedades, sin excepción, tenían su origen en la injusta organización social del capitalismo hasta el punto de que la propia sociedad capitalista era considerada una patología más.

La línea editorial de El Socialista, durante la década de 1880 y parte de la siguiente, abundaba en esta dirección. Con insistencia se apelaba a la explotación, la miseria y sus derivados (exceso de trabajo, hambre, vivienda insalubre, malas condiciones de trabajo, etc.) como las causas de que la enfermedad golpease con más fuerza a los obreros ${ }^{21}$. Especialmente sensibles se mostraban ante la diferente morbi-mortalidad entre clases sociales. En un artículo publicado en 1890, año especialmente duro para la población madrileña que pareció epidemias de gripe, viruela y cólera, se hacía una encendida denuncia de la miseria en que vivían los obreros ${ }^{22}$. Su autor reproducía una supuesta conversación con sus compañeros de tertulia en la que éstos, en tono de mofa, le habrían preguntado si los burgueses eran culpables del cólera. Su respuesta constituye una buena muestra de las posiciones del Partido Socialista sobre los orígenes de la enfermedad y la condición del trabajador en la sociedad capitalista. En ella afirmaba:

«Decís que no, necios; decís que no es culpable la sociedad que adoráis sin conocerla a fondo, de esa mortandad terrible,(...); creéis que no es responsable la burguesía triunfante de que así perezcan miles de infelices, segadas sus vidas por la afilada segur de una epidemia, a la que las condiciones en que aquéllos viven de miseria y abandono - que el aseo individual, por más que digan, no basta a evitar- proporciona medios eficaces de extender su acción destructora, de cebarse más y más en los desdichados seres que son su carne, su alimento más fácil de adquirir, su manjar predilecto. ¡Decís que el olvido en que los grandes tienen a los pequeños no es la causa ocasional de esas cifras que os aterran! De ellos, de ellos es la culpa de los infames egoístas que sólo piensan en huir del peligro dejando en él a los infortunados a quienes arrancaron a fuerza de coacciones cobardes, por lo disimuladas, los medios de evadir el contagio» ${ }^{23}$.

21. Campos Marín, Ricardo. Alcoholismo, Medicina y Sociedad en España (1876-1923). Madrid: CSIC; 1997, p. 192-197.

22. Fernández, Antonio. Epidemias y sociedad en Madrid. Madrid: Vicens Vives; 1985, p. 207-273.

23. El Socialismo y el Cólera. El Socialista, 3 Oct 1890; (239): 1. 
Tras esta declaración inicial el articulista continuaba con su denuncia genérica, explicando como las diferencias sociales incidían en el desigual impacto de la epidemia entre las clases sociales, responsabilizando a la actitud de la burguesía de la falta de salud de sus propios trabajadores:

«Aquellos sus obreros que consumen y acortan su existencia en el trabajo rudo, siempre sujetos a la tarea insufrible, aspirando el aire enrarecido de los talleres; metidos entre el fango de las lagunas, escondrijo de mortíferas enfermedades, tostándose en los campos a los ardores de un sol que abrasa; dados a labores que destrozan sus pulmones o merman su vida de otro modo (...); aquellos sus obreros a quienes se impone un sacrificio que no hay manera de eludir por el momento, el sacrificio de su salud y con él el de su vida, desprovistos de toda arma de defensa, sucumben a los golpes de la desventura, disfrazada de enfermedad contagiosa» ${ }^{24}$.

Para los redactores de El Socialista, la consecuencia lógica de tales condiciones extremas era que la salud era una utopía inalcanzable dentro del sistema capitalista. En una serie de artículos publicados entre noviembre de 1893 y agosto de 1894 con el título común de La Salud, lo expresaban con claridad en los siguientes términos:

«Los pobres no pueden tener salud; se lo prohíbe la sociedad, aunque se diga lo contrario. No hay obrero que gane lo bastante para comprar a su familia la cantidad de substancias albuminoideas, amiláceas, grasas y minerales indispensables al sostenimiento de la salud. (...) El aire, la luz, el calor, el terreno, la localidad, el clima y la habitación, son una serie de cosas que influyen directamente en la salud, pero a cuyos efectos perniciosos no pueden sustraerse los proletarios. Tienen que adoptar, aunque les sea perjudicial, el clima de la localidad donde encuentran limitado sustento y tienen -a la fuerza y pagando elevados alquileres - que aceptar las habitaciones que proporcionan los propietarios, aunque reúnan malas condiciones higiénicas. Y si analizamos más en detalle la vida humana en la actualidad, veremos cuan imposible es hoy conservar la salud, y como también son inaplicables ahora entre los desheredados los principios fundamentales de todas las ramas de la Higiene (...) En fin, que al estudiar hoy los higienistas procedimientos para la conservación y mejoramiento de la salud, tratan asuntos que han de aprovechar a las generaciones futuras; a aquellas generaciones que desconozcan la explotación y la desigualdad social» ${ }^{25}$.

24. El Socialismo y el Cólera, n. 23.

25. La Salud. El Socialista. 3 Nov 1893; (400): 2. 
No obstante, esta línea de pensamiento que en 1893 remitía a un futuro indeterminado los beneficios de la higiene y la salud para los obreros, ligándolas al advenimiento de la sociedad socialista, en apenas un lustro se abandonó y se sustituyó por otra que abogaba por la necesidad de que los obreros comprendieran y practicaran los principios de la higiene como forma de mejorar su vida y su calidad como militantes.

\section{La higiene, instrumento de dignificación obrera}

El radicalismo teórico de los socialistas españoles, plasmado en el rechazo a cualquier componenda reformista con la burguesía y en la firme creencia en el advenimiento de la revolución colectivista, fue progresivamente abandonado a lo largo de la década de 1890 en favor de una mayor adecuación entre los planteamientos teóricos defendidos y la práctica del Partido, caracterizada, pese al discurso revolucionario, por estar «constantemente dirigida a intentar mejoras en la precaria condición obrera» ${ }^{26}$ cómo lo demuestran las campañas de 1885-1886 a favor de la aplicación de la ley Benot sobre el trabajo infantil y la de 1886-1887 para lograr la implantación de la jornada de ocho horas. También el programa del Partido aprobado en 1888 recogía la necesidad de luchar a favor de una legislación favorable a los obreros ${ }^{27}$.

Además la constitución de la Unión General de Trabajadores en 1888, la decisión del Partido, a partir de la aprobación en 1890 del sufragio universal, de participar en las elecciones, las diferencias respecto a los anarquistas sobre el sentido del 1 de Mayo y la influencia de la tendencia general de la mayoría de las organizaciones de la II Internacional a aceptar la vía parlamentaria, fueron algunos de los principales motivos que determinaron el cambio ideológico del PSOE ${ }^{28}$.

Esta transformación ideológica se plasmó en la aceptación de la vía reformista, así como en la insistencia de reforzar la organización y propagar los ideales socialistas entre la clase obrera como medio de aumentar su

26. Castillo, Santiago. Hacia la mayoría de edad. (1888-1914). Historia de la Unión General de Trabajadores. Madrid: Publicaciones Unión; 1998, vol. 1, p. 93

27. Castillo, n. 26, p. 50-61; 92-93; Castillo, Santiago. El socialismo madrileño hace un siglo: Un anhelo de reformas. Arbor. 2001; 169 (666): 419-425.

28. Castillo, n. 27. 
conciencia de clase y de prepararla para la toma del poder en un futuro no definido. En 1895 El Socialista publicaba un articulo titulado «Las reformas son indispensables», donde se expresaba de forma significativa la metamorfosis ideológica que estaba teniendo lugar en el seno del socialismo español. A juicio del anónimo articulista la emancipación del proletariado no podía «conseguirse de golpe y porrazo» y se hacía necesaria, como «condición precisa para dar fin con el poder de la clase dominante» la «adopción de reformas que, mejorando la situación moral y material de la clase trabajadora, ponga a ésta en condiciones de vencer a los que la oprimen ${ }^{29}{ }_{\text {». }}$.

La mejora material y moral de la clase obrera se convertía en un objetivo imprescindible para que ésta aumentase su fortaleza física e intelectual y accediera al grado de conciencia y aprendizaje necesario para enfrentarse a la burguesía en condiciones más favorables. «Se impone alcanzar aquellas reformas que les den a ellos y a los suyos más medios de vida, más descanso y mayor conocimiento»-continuaba el artículo- para poder mantener con éxito su lucha contra los explotadores y preparar las soluciones que las circunstancias impongan ${ }^{30}$ ».

El interés del texto para el propósito de nuestro trabajo radica en la inclusión de elementos relacionados con la salud para explicar la necesidad de mejorar las condiciones de vida y de trabajo de los obreros por medio de reformas. Así, se explicaba que si el obrero estaba bien alimentado, descansaba las horas necesarias, aumentaba su salario y no padecía dolores físicos y morales, su inteligencia sería más fuerte y tendría mayor serenidad y capacidad para militar y luchar por su emancipación y la de su clase.

Juan José Morato ${ }^{31}$, Secretario General del Partido, plasmó perfectamente esa exigencia en su celebre conferencia «El deber de mejorar» dictada en el Centro Obrero de Madrid en diciembre de 1901. En ella pedía a los obreros que mejorasen en todos los terrenos de su vida para poder llevar a cabo su misión histórica y señalaba:

«Y si ponemos empeño en la tarea, veremos que cumpliendo el deber de mejorar nos vamos redimiendo lentamente. Mas sanos de cuerpo, tendremos más bríos para pelear, y sabremos templarnos en las adversidades, afrontándolas y encontrando en ellas bríos y empuje. Más inteligentes, se-

\footnotetext{
29. Las reformas son indispensables. El Socialista, 8 Nov 1895; (505): 2.

30. Las reformas son indispensables, n. 29

31. Sobre la figura de Juan José Morato véase Castillo, n. 8, p. 1-152
} 
remos mejores soldados de la revolución social, tendremos en todo trance más probabilidades de lograr la victoria en nuestros empeños. Con mayor elevación moral, tendremos más alta idea de nuestra dignidad, seremos más enérgicos defensores de ella» ${ }^{32}$.

Se producía así, un interesante giro, corroborado por otros artículos, que abría la puerta a que la miseria y la falta de salud dejaran de ser exclusivamente argumentos de denuncia del sistema para ser reinterpretados como rémoras para la lucha y emancipación proletaria. Siguiendo esta línea argumental la higiene y la salud adquirirán una nueva dimensión para el Partido Socialista. En 1902 de nuevo Juan José Morato aseguraba en La Nueva Era, desde una perspectiva marcadamente evolucionista y cientifista, que la historia era una «larga y dolorosa evolución» hacia el bienestar a la que la humanidad era «empujada consciente o inconscientemente, por fuerzas irresistibles, por fuerzas económicas y sociales, morales e intelectuales» de manera que:

«Las reformas inmediatas se ven preconizadas por hombres de todas confesiones religiosas y políticas, cuando no declaradas por la ciencia, condición de vida para el espíritu y para el cuerpo. Porque en este orden de consideraciones es muy de tener en cuenta que las ciencias que a la cultura del cuerpo y del espíritu se consagran - la Higiene y la Pedagogía, etc- concuerdan en sus irrefutables dictados con las reivindicaciones proletarias» ${ }^{33}$.

La introducción de la mejora individual en el discurso socialista permitió una mayor presencia de las cuestiones relacionadas con la higiene en el ideario del Partido.

Los discursos higienistas ya no aparecerán exclusivamente como algo ajeno, utópico e imposible de alcanzar en la sociedad capitalista. Los problemas de salud de los obreros no serán sólo un indicador de la injusticia social, de la miseria y de la explotación que padecía el proletariado, sino que también tendrán un componente personal de automejora, valorándose la mayor atención de cada obrero al mantenimiento de su salud como un acto solidario con el resto de compañeros en la lucha colectiva por el socia-

32. El deber de mejorar. Conferencia leída por J. Morato en el Centro Obrero de Madrid, el 21 de diciembre de 1901. El Socialista. 24 Ene 1902; (829): 2.

33. Morato, Juan José. Por distintos caminos. La Nueva Era; 1902, p. 7. 
lismo. El vigor y la salud física y mental serán desde entonces considerados atributos positivos y constitutivos de la identidad obrera ${ }^{34}$.

Merece la pena analizar con cierta profundidad algunas de las piezas clave de este proceso de aceptación de la higiene social e individual como valor social por parte de la élite del Partido y sus intentos por extenderlos al conjunto de la militancia porque ponen de manifiesto las contradicciones, ambigüedades y ajustes discursivos e ideológicos que ocasionaron a sus mentores, así como el creciente papel de mediadores culturales que comenzarán a tener algunos médicos entre el universo obrero y el mercado de trabajo.

Particularmente interesante a este respecto es la actitud que entre 1897 y 1900 mantuvo el PSOE hacia las propuestas de lucha antituberculosa del Dr. Moliner ${ }^{35}$. En abril de 1897 El Socialista se hizo eco de una conferencia que Moliner había impartido el 24 de enero de 1896 en el Ateneo Científico de Valencia bajo el título «Aspecto Social de la tuberculosis» ${ }^{36}$. Previendo que la publicación de un texto íntegramente leído por un médico burgués en un espacio de sociabilidad burguesa, podía provocar recelos entre los lectores del semanario o, tal vez como fruto de una discusión en su consejo

34. Sobre esta cuestión puede verse Girón Sierra, Álvaro. Metáforas finiseculares del declive biológico: degeneración y revolución en el anarquismo español (1872-1914). Asclepio. 1999; 51 (1), 247-273; Campos Marín, Ricardo; Martínez Pérez, José; Huertas, Rafael. Los ilegales de la naturaleza. Medicina y Degeneracionismo en la España de la Restauración (1876-1923). Madrid: CSIC; 2000, p. 218-235.

35. Sobre la figura de Moliner y su proyecto de hospital nacional puede consultarse Molero Mesa, Jorge. Francisco Moliner y Nicolás (1851-1915) y el inicio de la lucha antituberculosa en España. Asclepio. 1990; 42 (1): 253-279. Un dato interesante sobre Moliner es que fue Diputado a Cortes como independiente por Valencia en 1901 y como miembro del Partido Conservador en 1914. La información al respecto puede consultarse en Blasco Ibáñez, Vicente (1867-1928). ¡Diputado Blasco Ibáñez!: memorias parlamentarias. Álbum fotográfico de Vicente Blasco Ibáñez en páginas centrales. Madrid: Hijos de Muley-Rubio; 1999, p. 100. Tambien hay información en el Indice Historico de Diputados de la página web del Congreso de los Diputados:

http://www.congreso.es/portal/page/portal/Congreso/Congreso/SDocum/ArchCon/SDHistoDipu/. (Consultada el 3 ene 2011)

36. La edición original de dicha conferencia data de 1896. Moliner Nicolás, Francisco. Aspecto social de la tuberculosis. Discurso leído el día 24 de enero, en el Ateneo Científico de Valencia con motivo de la apertura del curso 1895-1896. Valencia: Imprenta Federico Domenech; 1896. El Socialista la reprodujo en su casi totalidad bajo el titulo Aspecto social de la tuberculosis en los números correspondientes al 2, 9, 16, 23 de abril y 7 y 14 de mayo de 1897. Citamos por la versión de El Socialista. 
de redacción, se incluyó una nota a pie de página justificando su publicación en los siguientes términos:

«Publicamos gran parte de este trabajo, no sólo por lo que enseña y por confirmar muchas de las opiniones que sostenemos los socialistas, sino por ser un terrible latigazo a la despiadada e imprevisora sociedad burguesa $»^{37}$.

Es cierto que, más allá de su condición burguesa, Moliner expresaba puntos de vista que genéricamente los socialistas podían asumir como propios. Así, consideraba que «la tuberculosis más que una enfermedad es una cuestión social, que tiene por clave la cuestión de la miseria ${ }^{38}$ ». Además acusaba a la burguesía de indiferencia ante un problema tan grave y juzgaba insuficientes los medios para combatirla, mostrándose particularmente duro con la Beneficencia a la que tachaba de «sistema anárquico» que se limitaba a cubrir «las apariencias de socorro» con el ingreso del enfermo pobre en un hospital donde a buen seguro fallecería ${ }^{39}$. Sin embargo, los argumentos de Moliner, que los redactores de El Socialista decían compartir, no implicaban una propuesta de reforma social profunda que paliara los problemas y causas sociales que detectaba como fuente de la tuberculosis. Finalmente su perspectiva era acusadamente iatrocéntrica, limitándose a proponer medidas preventivas y terapéuticas que dejaban de lado las reformas estructurales de la sociedad y otorgaban al médico y a la tecnología con la que contaba el papel central para solucionar el problema de la tuberculosis:

«Un reconocimiento periódico hecho por médicos competentes en los talleres, en los barrios obreros, en los presidios, en los cuarteles, en todo lugar en donde haya, por la aglomeración y la miseria, masa viva apropiada para la aglomeración y la miseria, masa viva apropiada para la fermentación del veneno; un sistema de colonias, de casas de profilaxia, de sanatorios, de casas de salud,(...) en donde encuentre el tuberculoso los positivos remedios salvadores y la sociedad en general las garantías contra la propagación del mortífero germen, son precisos para hacer frente a esa enfermedad terrible» ${ }^{40}$.

37. Aspecto social de la tuberculosis. El Socialista, 2 Abr 1897; (578): 3.

38. Aspecto social de la tuberculosis, n. 37.

39. Aspecto social de la tuberculosis, n. 37.

40. Aspecto social de la tuberculosis, n. 37 
Apenas dos años después, en noviembre de 1899, el Dr. Moliner impartió en el Centro Obrero de Madrid una de las primeras conferencias de temática sanitaria que fue ampliamente reseñada por El Socialista ${ }^{41}$. El objeto de la misma era exponer el proyecto de ampliación del sanatorio para tuberculosos pobres de Porta Coeli, que el mismo había creado un año antes, y solicitar a los obreros madrileños que siguieran el ejemplo de sus compañeros valencianos, suscribiendo «un céntimo diario» para llevarla a cabo. Tras su exposición, Moliner se reunió en privado con una Comisión del Centro Obrero para recabar su apoyo a la causa del sanatorio. El resultado fue un éxito pues los presidentes de las Sociedades del Centro Obrero, tras escucharle, «convinieron en que la empresa de fundar un sanatorio para tuberculosos era altamente conveniente para la clase obrera», redactando un documento de apoyo en el que señalaban:

«Los que suscriben, presidentes de las Sociedades que forman el Centro Obrero de Madrid, y asumen la confianza de más de trece mil obreros asociados, persuadidos de los beneficios que ha de reportar al Proletariado la creación en España de Sanatorios populares, que en gran número funcionan ya en el extranjero, como únicos medios para combatir la tuberculosis, que diezma nuestra clase, según determinan las conclusiones primera y cuarta del Congreso Internacional para el estudio de esta enfermedad celebrado últimamente en Berlín, unen su voto al de sus compañeros de Valencia, manifestado con la hermosa suscripción de los catorce mil céntimos diarios, y apoyan las gestiones que hace usted cerca de los Poderes públicos, encaminadas a conseguir del Estado, con las necesarias subvenciones, transforme el Sanatorio para tísicos pobres que ha fundado en Porta Coeli, en Sanatorio Nacional» ${ }^{42}$.

Por su parte, el cronista de El Socialista ahondaba en la misma línea, argumentando que el Partido Socialista al respaldar la iniciativa del Dr. Moliner no hacía otra cosa «que seguir el camino que ya nos trazaron otros partidos socialistas, que apoyan en sus países la idea de fundar y sostener por el Estado-único que puede hacerlo-Sanatorios nacionales para tuberculosos». Asimismo, aprovechaba para dignificar la actitud del proletariado madrileño, proclamando su superioridad moral porque, pese a su miseria, era capaz de sufragar una causa justa, mientras que la burguesía se mostraba timorata y poco proclive a contribuir al proyecto del sanatorio.

41. El sanatorio de Porta Coeli. El Socialista. 8 Dic 1899; (718): 3.

42. El Sanatorio de Porta Coeli, n. 41. 
Aunque no existe constatación documental que pueda demostrarlo, las razones esgrimidas por El Socialista para apoyar la obra de Moliner, muestran la posible existencia de reticencias internas a colaborar con una iniciativa privada que chocaba con los principios ideológicos del Partido. No hay que olvidar que fruto de la campaña emprendida por Moliner en 1898, el Sanatorio de Porta Coeli había sido reconocido por Real Orden de 3 de marzo de 1899 como obra de Beneficencia particular y, que al tiempo que visitaba a los socialistas, mantuvo contactos con varios ministros y con la propia reina para conseguir su apoyo, apelando al carácter benéfico de su obra $^{43}$. Quizá por ello, dos semanas después El Socialista matizaba su sostén a Moliner. Le agradecían su iniciativa y reiteraban su interés en colaborar con él pero le advertían que no le seguirían «en todas sus gestiones ${ }^{44}$ ». Los matices introducidos intentaban distanciar al Partido Socialista de una posible mala interpretación de sus intenciones. El problema fundamental que se le planteaba era como justificar su apoyo a una iniciativa filantrópica de corte benéfico. Ideológicamente los socialistas siempre expresaron su rechazo y horror hacia la beneficencia pública y privada. Los motivos de su actitud refractaria fueron variados, pero todos ellos tenían como nexo común la denuncia de la mala calidad de la asistencia recibida, así como la conciencia de que el recurso a ésta era denigrante para su condición de trabajadores, pues estaba dirigida a los indigentes y no constituía un derecho sino un mero acto caritativo de la burguesía ${ }^{45}$.

Los argumentos que utilizaron en el caso del Dr. Moliner son muy interesantes e indicativos de la tensión interna que debía respirarse en el PSOE, pues atrapado en la campaña del céntimo diario justificaba su posición en la consideración de que los obreros no querían, ni pedían el sanatorio «a titulo gracioso» ni lo solicitaban «de la benevolencia, ni de la caridad de nadie», sino que lo reclamaban y exigían «como parte de lo mucho que les es debido ${ }^{46_{»}}$. Por tanto, el sanatorio era un derecho que los obreros reclamaban con fuerza y los céntimos recaudados representaban a cada uno de los militantes y mostraban la creciente fuerza del socialismo ${ }^{47}$.

\footnotetext{
43. El Sanatorio de Porta Coeli. El Imparcial, 26 Nov 1899; (11708): 1.

44. El Sanatorio de Porta-Coeli. El Socialista. 29 Dic 1899; (721): 2.

45. Sobre el rechazo que suscitaba la beneficencia entre los socialistas puede verse Molero Mesa, Jorge. ¡Dinero para la Cruz de la vida! Tuberculosis, beneficencia y clase obrera en el Madrid de la Restauración, Historia Social. 2001; 39: 31-48.

46. El Sanatorio de Porta Coeli, n. 44.

47. El Sanatorio de Porta Coeli, n. 44.
} 
Pero las dificultades para explicar y justificar continuaron a juzgar por el tono del nuevo artículo dedicado al Sanatorio un año después, donde se retomaba el argumento de que era un derecho de los obreros y se insistía en que no era la solución al problema de la tuberculosis sino un paliativo «que dulcifica los males ocasionados por una plaga social», cuya solución definitiva vendría cuando se procediera al «reparto más justo de las riquezas $^{48} \gg$. Si bien, se matizaba que el trabajo por las mejoras de la clase obrera y la revolución no impedía el apoyo a proyectos concretos como el del Dr. Moliner, que repercutían en beneficio de los trabajadores:

«Con ello, sobre trabajar para el beneficio inmediato de la clase obrera, se demuestra andando que nada de lo que a esta clase beneficie nos es indiferente, antes es recibido con aplauso y simpatía por nosotros y prestamos nuestro apoyo y adhesión, bien que ésta sea condicional y jamás de súplica ni de ruego. Ayudemos pues al Dr. Moliner en sus gestiones, hagamos constar nuestra voluntad de que el Sanatorio tome el desarrollo que la humanidad y la conveniencia social reclaman; que se sepa que ansiamos ver convertido en deber del Estado lo que hoy es producto de la iniciativa y del apoyo individual. Así cumplimos nuestros deberes de socialistas y de obreros que se preocupan de su suerte» ${ }^{49}$.

Simultáneamente a la campaña de Moliner, El Socialista recogió en sus páginas una interesante polémica con el Dr. Felipe Ovilo ${ }^{50}$ que finalizó con la organización de un Curso de Higiene Vulgar dirigido a los militantes socialistas.

La controversia se inició con el artículo que publicó en El Liberal a finales de octubre de 1899, al que me he referido al principio del trabajo ${ }^{51}$.

Entre los meses de septiembre y noviembre Ovilo publicó una serie de seis trabajos bajo el título común de «Crónicas de Higiene Vulgar», en los que abordaba diferentes temas relacionados con la falta de higiene en Madrid, lamentándose del desinterés institucional y social, especialmente de las clases directoras, por remediar la elevada mortalidad de la capital que dicha situación producía. Sus posiciones se circunscribían en el marco de un discurso higienista bastante ortodoxo, consistente en describir los problemas

\footnotetext{
48. Porta-Coeli. El Socialista. 9 Nov. 1900; (766): 2.

49. Porta-Coeli, n. 48.

50. Sobre la figura de Felipe Ovilo Canales puede consultarse el libro de Martínez Antonio, Francisco Javier. Intimades de Marruecos. Miradas y reflexiones de médicos españoles sobre la realidad marroquí a finales del siglo XIX. Madrid: Miraguano Ediciones; 2009; p. 22-30

51. Crónicas de Higiene Vulgar, n. 1
} 
de higiene y salud de la población, en dictaminar sus causas y finalmente en proponer una serie de medidas, en general consejos, para mejorar y superar la situación de partida. Sin embargo, en su cuarta crónica acusó a las Sociedades Obreras de Madrid de descuidar los asuntos relacionados con la higiene y de no presionar a las autoridades para que cumplieran con su deber, señalando que «podrán decir las Asociaciones obreras que si no demandan lo que se indica es porque desconocen esas necesidades». Para paliar esas carencias se ofrecía, en nombre de El Liberal, a impartir un curso de higiene de un «modo claro, sencillo y comprensible para todos», a los comisionados que eligieran las asociaciones obreras «para aprender tales conocimientos con la obligación de trasmitírselos a sus compañeros ${ }^{52}$ ».

La respuesta de los socialistas a Ovilo llegó en forma de artículo el 10 de diciembre de 1899. Indignados ante las acusaciones vertidas por el médico, se le contestaba que la higiene no sólo no era incompatible con los ideales que defendían los socialistas, sino que formaba parte de la lucha obrera por su emancipación y mejoramiento material y moral:

«No tienen los obreros muchos conocimientos de higiene, porque su situación económica no se lo permite; pero de eso a que en absoluto desconozcan la higiene y no se preocupen de ella, hay una diferencia notable. Lo mismo las Sociedades obreras de Madrid que las de todas partes que tienen carácter de resistencia se proponen mejorar moral y materialmente la condición de sus asociados ¿Es posible que los obreros mejoren materialmente su condición sin que pongan en práctica algún principio de higiene? Parécenos que no» ${ }^{53}$.

Igualmente, frente al enfoque estrecho de la higiene defendido por Ovilo, la perspectiva socialista era más amplía, defendiendo y reivindicando la legislación protectora del trabajo como abiertamente higiénica:

«Entérese el Dr. Ovilo, si le es posible de los puntos que comprende la Legislación protectora del trabajo acordada en el Congreso internacional de París, y verá como muchos de ellos están calcados en principios higiénicos. Pues bien: de esa Legislación son defensoras las Sociedades obreras de resistencia ${ }^{54}$.

52. Crónicas de Higiene Vulgar, n. 1

53. La higiene y las sociedades obreras. El Socialista. 10 Nov 1899; (714): 2.

54. La higiene y las sociedades obreras, n. 53. 
En su contestación los socialistas recogían las que serían sus principales líneas de actuación en materia de salud en los años siguientes. La enfermedad se encuadraba en un contexto socioeconómico amplio y se recalcaban, como siempre habían hecho, la miseria y la explotación como origen de la misma. Ahora bien, la solución no pasaba tanto por llevar a cabo la revolución social, relegada a un futuro incierto, como por obtener reformas sociales que paliaran las causas de la enfermedad y por tanto mejorasen las condiciones de vida del obrero. En consonancia con esta postura, la higiene se interpretaba en un sentido amplio donde tenían cabida tanto los aspectos más sociales como la legislación reformista encaminada a mejorar la calidad de vida y de trabajo de los obreros, como los aspectos individuales de cuidado del propio cuerpo y del hábitat familiar.

Sin embargo, los socialistas madrileños aceptaron la invitación de Ovilo, acordando organizar el mencionado curso, según informaba con entusiasmo El Liberal del 1 de diciembre:

«Esta actitud de los obreros constituye el mayor elogio que, acerca de la oportunidad y trascendencia del pensamiento felicísimo del doctor Ovilo, pudiéramos hacer, y es además gallarda muestra del afán que sienten los hijos del trabajo por asimilarse las ideas cuyo estudio se relaciona más directamente con la necesidades de su vida física y moral. No puede menos de halagarnos ese movimiento de las clases obreras, porque significa una tendencia en sentido regenerador digna de aplauso, y acorde con los principios constantemente sustentado por nosotros» ${ }^{55}$.

El 5 de diciembre comenzó en los salones de El Liberal el Curso de Higiene Vulgar con la presencia de los comisionados enviados por las distintas sociedades obreras del ámbito socialista. Tanto El Liberal como El Socialista informaron de las distintas sesiones, mostrando un gran interés por las mismas. Aunque el curso estaba programado para bastantes sesiones finalmente sólo se impartieron tres sin que las partes explicaran las causas de su suspensión. Las dos primeras sesiones se centraron en analizar los nocivos efectos que sobre la salud de los obreros tenía la mala ventilación de sus lugares de trabajo, explicando el funcionamiento de la respiración humana y la importancia del aire para el cuerpo humano. Ovilo reconocía que numerosos talleres y fábricas no reunían las condiciones deseadas de

55. Higiene para obreros. Conferencias del doctor Ovilo. El Liberal. 1 Dic 1899; (7364): 1. 
ventilación, produciéndose un lento envenenamiento de los trabajadores. Sin embargo, no proponía soluciones a dicho problema y se limitaba a recordar a los trabajadores que «el aire puro es la primera necesidad de la vida» $y$ que no «hay nadie ni puede haber alguien tan insensato que os pueda negar cosa tan indispensable como es una buena ventilación en los locales donde ganáis el pan de cada día ${ }^{56}$ ». Como colofón a su ciclo de conferencias, Ovilo pasó un cuestionario a los obreros para recabar información sobre las condiciones de trabajo de los distintos oficios ${ }^{57}$.

Pese a la distancia ideológica de los planteamientos de Ovilo, El Socialista acogió bien la actividad, solicitando que se le de «un aplauso por su generosa y fructífera iniciativa, verdadera obra civilizadora». El cronista continuaba señalando que «el sabio higienista» se dirigió al público «en tono liso y llano y con términos vulgares» consiguiendo que fuera «escuchado con grande atención» por los oyentes. Junto a los parabienes que le dedicaba también le criticaba en tono amable algunos aspectos de sus conferencias, atribuyendo sus errores al «buen deseo»y a un estudio del «problema social» en «una extensión muy limitada ${ }^{58}$ ». Por su parte, Ovilo no escatimaba elogios para los obreros por sus deseos de instruirse, atribuyéndoles un mayor deseo «de hacer cuanto pueden por conservar la salud y prolongar la vida, que es la higiene», que a las clases «que debieran ir a la cabeza de todo progreso científico y social ${ }^{59}{ }$.

Podría pensarse que la adhesión, más o menos matizada, de los socialistas a visiones liberales de la higiene fue una mera aceptación y adaptación al modelo médico hegemónico que, abrió la puerta a la colonización y domesticación de la clase obrera. Sin embargo, lejos de producirse una actitud mimética hubo una «interacción dinámica entre» el discurso hegemónico de la medicina y las señas de identidad de la clase obrera que los socialistas trataban de construir ${ }^{60}$. En el proceso de construcción de una

\footnotetext{
56. Conferencia de higiene vulgar. El Liberal. 20 Dic1899; (7383): 1

57. El cuestionario puede consultarse en Curso de Higiene vulgar. El Socialista. 29 Dic 1899; (721): 3. La redacción del periódico comentaba dicho cuestionario en los siguientes términos: «Excusamos decir que si nos envían nuestros compañeros respuestas las pondremos en mano del Dr Ovilo, y que nos alegraríamos infinito de que asunto tan importante se tomara con interés».

58. Curso de higiene vulgar. El Socialista. 15 Dic 1899 (719): 3-4

59. Curso de higiene vulgar, n. 58; Curso de higiene vulgar. El Liberal. 6 Dic 1899; (7369): 1.

60. En este sentido, me han resultado especialmente útiles las consideraciones de Llona González, Miren. La construcción de la identidad de clase obrera en el País Vasco. Género y respetabilidad
} 
identidad de clase positiva y de dignificación de la clase obrera, la higiene y la salud jugaron un importante papel al ser considerados por la élite socialista instrumentos para la mejora personal y colectiva de los obreros. En ese sentido, me interesa destacar cómo y para qué fines se produjo el proceso de apropiación y reelaboración del discurso higienista.

A este respecto, una cuestión interesante es la manera en que se plantearon en el seno del socialismo español las conferencias de temática higienista y su difusión en las páginas de El Socialista. Los relatores de las mismas intervenían constantemente con comentarios cuyo propósito era acercar el discurso del médico burgués a los lectores del periódico obrero, presentándolo como un evento importante para la formación de los militantes. Así, por medio de notas introductorias, observaciones, comentarios y recomendaciones dirigían la lectura recontextualizando en el ámbito ideológico socialista un discurso que en origen les era ajeno. Se produce, así, un proceso de apropiación del mismo, o de algunas de sus partes, que se consideraban útiles para los fines de la causa socialista. Este complejo fenómeno de resignificación discursiva no tuvo lugar sólo en el campo de la higiene, sino que fue mucho más amplio, manifestándose especialmente en el terreno literario. Pilar Bellido explica que «al publicarse en semanarios socialistas» la obra de escritores burgueses entraba «a formar parte del marco poético» propugnado por el socialismo, añadiéndose «los contenidos de clase que le faltaban» en origen ${ }^{61}$. Pero la recontextualización ideológica de los discursos, a mi juicio, no se producía sólo en los medios escritos. El espacio donde se celebraban los cursos, las conferencias y cualquiera de las actividades relacionadas con la higiene era en si mismo un factor, por su enorme poder simbólico, de contextualización ideológica. En este sentido, el salón de actos del Centro Obrero o de la Casa del Pueblo contribuía poderosamente a la apropiación cultural ${ }^{62}$.

de clase, dos realidades inseparables. Vasconia: Cuadernos de Historia-Geografía [artículo en Internet]. 2006 [citado 23 Feb 2010]; 35: 287-300

61. Bellido Navarro, Pilar. Literatura e ideología en la prensa socialista (1885-1917). Sevilla: Ediciones Alfar; 1993, p. 98.

62. Sobre la importancia de los Centros Obreros y las Casas del Pueblo como espacios de desarrollo de la cultura obrera y construcción de su identidad pueden verse entre otros: Tiana Ferrer, Alejandro. Maestros, misioneros y militantes. La educación de la clase obrera madrileña, 1898-1917. Madrid: Ministerio de Educación y Ciencia-CIDE, 1992; Guereña, Jean-Louis. Las Casas del Pueblo y la educación obrera a principios del siglo XX. Hispania. 1991; 51/2, (178): 645-692; Serrano, Carlos. Le Parti Socialiste espagnol et la culture (1890-1910). In: Guereña, Jean-Louis; Tiana, Alejandro, eds. Clases populares, cultura, educación. Siglos XIX-XX. Coloquio hispano-francés (Casa de Velázquez, Madrid, 15-17 junio de 1987). Madrid: Casa de 
Pero esta apropiación hay que circunscribirla en un contexto sociocultural de mayor alcance como es la construcción de una identidad obrera respetable, estrechamente ligada a la constitución de una cultura propia que conllevaba a su vez la creación de espacios de sociabilidad y de medios de producción y difusión escrita. Dicha cultura obrera que pretendía presentarse como alternativa a la cultura dominante, rechazaba tajantemente las manifestaciones de la «cultura popular» e intentaba apropiarse de la cultura dominante. Sin embargo, la apropiación tenía como contrapartida una importante dependencia de la cultura dominante a la que pretendía contrarrestar ${ }^{63}$. En este sentido, el interés por la higiene y la salud del obrero que mostró el Partido Socialista como instrumento de mejora colectiva y personal, puede enmarcarse en un intento amplio de dignificación y de conquista de una respetabilidad de clase que le era negada por el discurso estigmatizador de la burguesía y de la clase media, bien representado por los textos de los médicos higienistas.

Un buen ejemplo de este complejo proceso sería el artículo titulado «En buen camino» que publicó El Socialista el 15 de diciembre de 1899. El artículo comparaba los deseos de aprender y de superarse de los obreros, demostrada en su interés por los eventos culturales, con la dejadez de los burgueses. Para ilustrar dichas diferencias comenzaba reseñando el éxito de las conferencias de Ovilo y de Moliner entre los obreros, subrayando el respeto y el silencio con que las habían escuchado, actitud bien distinta a la que mostraban los burgueses por la cultura ${ }^{64}$. Este comportamiento se consideraba como un signo inequívoco de que la clase obrera iba «a ser la dueña del mundo», pues «su seriedad, su ansia de saber, su fe» le daría finalmente «la superioridad sobre las demás clases ${ }^{65}$ ». Así pues, las conferencias de los dos ilustres médicos se inscribían en una estrategia amplia que buscaba la instrucción de los obreros como medio para mejorar su condición moral y su preparación para la futura revolución. Esa mejora formaba parte también de la estrategia de construcción de una identidad obrera respetable a los ojos del resto de la sociedad.

Velázquez; 1990, p. 457-466; De Luis Martín, Francisco; Arias González, Luis. Las Casas del Pueblo socialistas en España (1900-1936): un estudio social y arquitectónico. Barcelona: Ariel; 1997. Más recientes son el mencionado libro colectivo Centenario de la Casa del Pueblo de Madrid, n. 2.

63. Serrano, Carlos. Cultura Popular/Cultura Obrera en España alrededor de 1900. Historia Social 1989; 4: 21-31.

64. Por buen camino. El Socialista. 15 Dic 1899; (719): 1.

65. Por buen camino, n. 64 . 
Estrechamente ligado a los intentos de dignificación y construcción de una identidad y cultura obrera independiente, el socialismo español potenció en los años de cambio de siglo la colaboración con los intelectuales organizando diferentes actos como cursos y conferencias en que eran los protagonistas o, simplemente publicando sus artículos en la prensa socialista ${ }^{66}$. En esta línea, hay que circunscribir los cursos de higiene impartidos por médicos en el Centro Obrero de Madrid con el objetivo de ilustrar y educar a los trabajadores.

Así entre febrero y abril de 1902 el Inspector de Sanidad Provincial Dr. Carlos Vicente, impartió en el salón principal del Centro Obrero un ciclo de ocho conferencias sobre «La Higiene preventiva de las enfermedades infecciosas» en las que explicó como actuaban los microbios en el organismo humano, recomendando la limpieza corporal, la higiene de la vivienda y la destrucción de «toda clase de insectos» como método de combatirlos. ${ }^{67}$ Asimismo, dedicó una sesión exclusivamente a la tuberculosis, indicando que los medios «para preservarse de ella» eran la abstinencia en el consumo de bebidas alcohólicas, el uso de escupideras para evitar el contagio y los paseos dominicales por el campo como contrapartida a la insalubridad de la habitación. ${ }^{68}$ La higiene doméstica fue objeto también de una sesión monográfica. Las medidas individuales que los obreros podían aplicar para mejorar sus condiciones higiénicas y conservar mejor su salud eran el mensaje central de las conferencias. Según las crónicas de El Socialista, corroboradas por otras de la prensa generalista, aquellas eran seguidas con enorme interés por los obreros que abarrotaban los sábados el salón grande del Centro de Sociedades Obreras ${ }^{69}$. Su carácter divulgativo quedaba patente en la utilización de un aparato de proyección, propiedad del Hospital de

66. Castillo, n. 3

67. En el Centro Obrero. Higiene preventiva. El Socialista. 21 Feb 1902; (833): 3.

68. En el Centro Obrero. Higiene preventiva. El Socialista. 12 Mar 1902; (836): 3.

69. «Con mayor auditorio, si cabe, que en las anteriores, dió el sábado último su tercera conferencia sobre "Higiene preventiva contra las enfermedades infecciosas" el señor D. Carlos de Vicente, en el salón grande del Centro de Sociedades Obreras. La importancia de la materia tratada despierta gran interés en los trabajadores madrileños, quienes seguramente seguirán en la medida de sus fuerzas los acertados consejos que para la conservación de la salud les da el señor de Vicente (...) Es grata demostración de la cultura que van adquiriendo los obreros, el interés que éstos demuestran en atender a las personas que en estas conferencias les proporcionan muy útiles enseñanzas», En el Centro Obrero. Higiene Preventiva, El Socialista. 28 Feb 1902 (834): 3. Sobre la importancia de los cursos de higiene de Carlos de Vicente y la masiva asistencia de los obreros a los mismos pueden verse también: Dr. A. Muñoz. Higiene 
San Juan de Dios, para mostrar imágenes ilustrativas del tema abordado en cada conferencia, así como en las preparaciones micrográficas que los asistentes al curso podían ver en el microscopio al finalizar cada sesión ${ }^{70}$. El ciclo de cursos fue un éxito, pues inmediatamente se publicaron en forma de libro, conociendo al menos dos ediciones en el mismo año ${ }^{71}$. Además, la asistencia de público debió impresionar al Dr. de Vicente, que envió una carta a la redacción de El Socialista, agradeciendo a los obreros su interés por las conferencias y manifestando admiración hacia la clase obrera por sus elevadas «cualidades morales e intelectuales ${ }^{72}$ ». El reconocimiento del Dr. de Vicente y de periódicos como el El Heraldo de Madrid y El Imparcial a la actitud y cualidades de los obreros que acudieron a las conferencias suponía para los socialistas la demostración de su capacidad organizativa y de la dignidad de la clase obrera frente a la burguesía ${ }^{73}$.

Tras el curso del Dr. de Vicente, el doctor Pérez Cano tomó el relevo publicando en El Socialista una larga serie de artículos titulados «La higiene del Obrero», que en realidad se centraron en la higiene bucal. Pese a su intención manifiesta de hacer algo práctico por los obreros que los leyeran, su tono era excesivamente técnico y tedioso. Así, describía el aparato digestivo, las enfermedades típicas de la boca, aconsejaba sobre la dentición infantil y relacionaba ciertas profesiones que manejaban sustancias tóxicas como el mercurio y el fósforo con diversas patologías bucales. Como transfondo de todo ello recomendaba encarecidamente a los obreros que se lavaran los dientes como medida preventiva ${ }^{74}$. Para contextualizarlos en el marco ideológico de los lectores socialistas, Pérez Cano en su primer artículo mencionaba oportunamente a Marx como impulsor de la sociología para

Popular. Heraldo de Madrid. 12 feb 1902; (4017): 1; Una campaña hermosa. El Imparcial. 25 Abr 1902; (12.588): 2 .

70. En el Centro Obrero. Higiene preventiva. El Socialista. 18 Abr 1902.

71. De Vicente, Carlos. Higiene popular: microbios y enfermedades: defensas naturales del organismo: desinfección: conferencias públicas dadas en el Centro de Sociedades Obreras. Madrid: Fortanet; 1902. Hemos consultado la segunda edición del mismo.

72. En el Centro Obrero. Higiene preventiva, n. 70. También la prensa generalista alabó la actitud de las Sociedades Obreras y de sus militantes, subrayando la necesidad de elevarse que tenían y el deber de instruirlos que tenían las clases dirigentes. Dr. A. Muñoz. Higiene Popular, 69 (4017): 1; Una campaña hermosa, n. 69

73. Muñoz, n. 69; Una campaña hermosa, n. 69.

74. La serie de artículos de Pérez Cano, se publicaron en El Socialista desde finales de julio de 1902 hasta mediados de enero de 1903, sufriendo una interrupción en septiembre y octubre de 1902. 
indicar que esta ciencia junto con la higiene marcaban «la línea de conducta que debiera seguir la Humanidad», para con enorme habilidad equipararlas con los objetivitos del socialismo:

«Hay más: si el Socialismo lanza a los cerebros un axioma: "haz conscientemente el bien de todos, el bien colectivo", también dice la Higiene: "cuida de tu aseo, de tu policía personal, se metódico, odia el alcohol... El higienismo particular, por otra parte, es colectivo en cuanto el bien resulta para todos, se evita la infección, la sepsis, en lenguaje científico, se mata el microbio; el Socialismo, no pudiendo dejar de ser higienista, rechaza los cerebros incultos o anhela pulimentarlos. (...) Dicho esto podemos afirmar rotundamente, en general, que todo preocupado por el bien del hombre, es tan buen sociólogo como higienista» ${ }^{75}$.

En otra conferencia impartida en enero de 1903 sobre el «Concepto higiénico de limpieza», el Dr. Ulibarri, calificado como correligionario del Partido, de nuevo con el salón del Centro Obrero abarrotado, proponía una serie de consejos higiénicos que los obreros podían aplicar en su vida cotidiana para conservar su salud. El hecho de que fuera militante era ya un importante factor para encuadrar ideológicamente su discurso en los parámetros socioculturales de sus oyentes. Pero además, sus argumentos para justificar la necesidad de practicar la higiene conectaban con la línea ideológica del Partido, al advertir que si bien las causas de la enfermedad no desaparecerían hasta que cambiase «el régimen económico» era necesario aplicarse en evitar en la medida de lo posible el $\mathrm{mal}^{76}$.

La relación entre las prácticas higiénicas y los buenos militantes socialistas era, por tanto, un argumento de peso que contribuía a legitimar el discurso médico ante la militancia. Este tipo de discurso que equiparaba la higiene y la salud con la extensión del socialismo jugará a partir del cambio de siglo un papel esencial de puente entre el mundo obrero y el higienismo. Un buen ejemplo de ello, son los argumentos que El Socialista empleó durante la epidemia de viruela de 1900 para convencer a sus militantes de la necesidad de vacunarse, vinculando la vacuna a la mejora moral del proletariado, a su respetabilidad y a la lucha por el socialismo:

75. Pérez Cano, Vicente. La Higiene del Obrero. El Socialista. 25 Jul 1902; (855): 3

76. En el Centro Obrero. Concepto Higiénico de la limpieza. El Socialista. 23 Ene 1903. 
«Interesado como estás en la tarea de redimirte del mal físico, moral e intelectual - que no otra cosa quiere el Socialismo-, y trabajando como trabajas por conquistar cada día un poco más de bienestar, si mediante una levísima molestia y el sacrificio de dos o tres minutos ganas una probabilidad de llegar a viejo, no serías buen soldado de la Revolución si la desperdiciaras. A más de que llamarse socialista obliga a respetar y a cumplir los mandatos de la ciencia. (...) ¡Conque a vacunarse tocan, y a vacunar a tu familia, y a decidir que a tus conciudadanos para que lo hagan! (...). Que no se diga que los obreros son enemigos de la higiene y de la previsión!» 77 .

\section{Conclusiones}

En las páginas precedentes he intentado demostrar la complejidad de las concepciones en materia de salud y de higiene de los socialistas españoles. He procurado hacer una lectura política de las mismas y del interés mostrado por los responsables del PSOE desde una perspectiva sociocultural, incidiendo en que, lejos de asumir acríticamente los discursos médicos, los reutilizaron y resignificaron, confiriéndoles la perspectiva de clase y de lucha obrera que originalmente les faltaron. Así, la higiene en el ámbito socialista fue poliédrica.

La constatación de la falta de condiciones higiénicas y sanitarias en la vida cotidiana de los obreros fue un acicate y argumento para denunciar la sociedad presente y pergeñar las virtudes de la futura sociedad socialista en la que todos los obreros disfrutarían de la misma. Pero también, desde mediados de la década de 1890 se implementó una estrategia política más amplia que pasaba por la mejora individual y colectiva, física y moral, de los militantes socialistas. En este contexto, la higiene y la salud se convirtieron en valores y en elementos esenciales de la dignificación e identidad de la clase obrera y, paralelamente, en la expresión de un profundo anhelo de ampliación de sus derechos sociales y políticos.

En los años siguientes al breve periodo estudiado, los asuntos relacionados con la salud y la higiene aumentarían exponencialmente en los medios socialistas con la novedad de ampliar su ámbito de acción al menos a tres campos: las realizaciones prácticas, como la fundación de la Mutualidad Obrera, con el objetivo de garantizar la asistencia médica y farmacéutica 
a sus militantes; la presencia en las instituciones y organismos creados por el Estado para llevar a cabo las reformas sociales; y las luchas directas por mejorar las condiciones de vida del obrero como fueron las campañas contra el impuesto de subsistencias de 1904-1905 y 1911. 